\title{
Response to the letter to editor: 24-h urine osmolality should be used in combination with other urine parameters in urolithiasis patients
}

\author{
Ho Won Kang ${ }^{1,2} \cdot$ Sang-Cheol Lee ${ }^{1,2}$ (])
}

Received: 7 June 2019 / Accepted: 10 June 2019 / Published online: 19 June 2019

(c) Springer Nature B.V. 2019

\section{Editor,}

We appreciate the valuable comment entitled "24-h urine osmolality should be used in combination with other urine parameters in urolithiasis patients" by Zhao and Yang [1].

The authors accurately describe the important considerations. First, the threshold level of 24-h UOsm in our study was based on single-center experience and may be arbitrary. We also concede that our UOsm cut-off value may not be possible to generalize to other populations. As mentioned by the authors, upper metastable limit osmolality might evaluate individual lithogenic capability and identify patients needing more aggressive hydration therapy [2].

Second, response to the author's query, we did not obtain repeated 24-h urine sample. Repeated 24-h urine collection is not feasible considering patients' compliance in real practice. Repeated urine metabolic tests are performed in heavy stone formers, but the numbers are insufficient for analysis. Instead, spot urine UOsm may be a good alternative, and we described it in the manuscript [3].

The most important issue raised by the author is that 24-h UOsm, as an index of hydration status, could not provide sufficient information in regard to urine $\mathrm{PH}$, solute saturation and individual lithogenic capability. We also agree with the author's suggestion that 24-h UOsm should be used in combination with the other urine parameters such as $\mathrm{pH}$, solute saturations, and upper metastable limit osmolality given the complexity of stone disease [2].

To prevent or reduce the recurrence of stone formation, adequate fluid intake is undisputed modification [4]. To monitor and improve compliance with hydration therapy,

Sang-Cheol Lee

1scuro@chungbuk.ac.kr

1 Department of Urology, College of Medicine, Chungbuk

National University, 776 1sunhwan-ro, Seowon-gu,

Cheongju, South Korea

2 Department of Urology, Chungbuk National University

Hospital, Cheongju, South Korea practical representative urinary indices may be crucial. Our findings provide important evidence that can be used to guide recommendation regarding adequate fluid intake.

Acknowledgements All authors state that they have no commercial interests in this paper.

\section{Compliance with ethical standards}

Conflict of interest No potential conflict of interest was reported by the authors.

\section{References}

1. Zhao Y, Yang L (2019) Twenty-four-hour urine osmolality should be used in combination with other urine parameters in urolithiasis patients. Int Urol Nephrol. https://doi.org/10.1007/s11255-01902198-y

2. Porowski T, Kirejczyk JK, Mrozek P, Protas P, Kozerska A, Labieniec L, Szymanski K, Wasilewska A (2019) Upper metastable limit osmolality of urine as a predictor of kidney stone formation in children. Urolithiasis 47(2):155-163. https://doi.org/10.1007/ s00240-018-1041-2

3. Kang HW, Seo SP, Ha YS, Kim WT, Kim YJ, Yun SJ, Kim WJ, Lee SC (2019) Twenty-four-hour urine osmolality as a representative index of adequate hydration and a predictor of recurrence in patients with urolithiasis. Int Urol Nephrol. https://doi. org/10.1007/s11255-019-02108-2

4. Gul Z, Monga M (2014) Medical and dietary therapy for kidney stone prevention. Korean J Urol 55(12):775-779. https://doi. org/10.4111/kju.2014.55.12.775

Publisher's Note Springer Nature remains neutral with regard to jurisdictional claims in published maps and institutional affiliations. 